\title{
Prospective Randomized Blinded Study to Compare Laparoscopic and Open Inguinal Hernioplasty
}

\author{
Mohd. Ilyas ${ }^{\circledR}$, Venkat Vaijnath Cholleti ${ }^{\odot}$ \\ Assistant Professor, Department of Surgery, Surabhi Institute of Medical Sciences, Siddipet, Mundrai, Telangana, India.
}

\section{Abstract}

Background: Hernia is one of the common surgical problems. Repair of inguinal hernia is one of the commonest surgical procedures worldwide, irrespective of country, race or socio-economic status and constitutes a major health-care in every country. Subjects and Methods: This is a randomised prospective study done over 50 patients in the department of general surgery of Kamineni hospitals, LB Nagar, Hyderabad during the period of October 2010 to August 2012 with the aim to compare laproscopic inguinal hernia repair and open inguinal hernia repair with regards to post-operative pain, surgical site infections, hospital stay and time taken to return to work, by a randomized study. Results: Compare laparoscopic and mesh inguinal hernia repairs, there is no significant difference in early assessment with regards to duration of operation, post-operative pain, analgesic requirements on the day of surgery and first post-operative day, hospital stay, return to daily and normal activities and post-operative complications. Conclusion: Laparoscopic mesh hernioplasty still remains to be validated with larger number of patients and longer duration of follow up.

Keywords: Inguinal Hernia Repair, Laproscopy, Hernia

Corresponding Author: Venkat Vaijnath Cholleti, Assistant Professor, Department of Surgery, Surabhi Institute of Medical Sciences, Siddipet, Mundrai, Telangana, India.

E-mail: venkat_vaijnath@yahoo.com

Received: 5 February 2020

Revised: 19 March 2020

Accepted: 31 March 2020

Published: 5 July 2020

\section{Introduction}

Hernia is as protrusion of a viscus or part of viscus through a natural or acquired defect in the wall of its containing

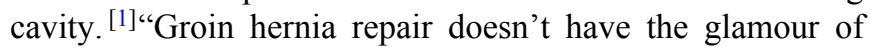
whipple or of a heart transplant but in terms of preserving years of useful life, in sheer volume, is one of the most important surgical procedures"- dr. Jonathan e. Rhoades. ${ }^{[2]}$

Starting from the beginning of modern anatomic hernia surgery, recurrences have plagued and frustrated surgeons of all ages, experience, skill and nationality. ${ }^{[3]}$

Soon after the introduction of synthetic plastic mesh in the 1950 's surgeons began experimenting with its use in bridging tissue defect. ${ }^{[4]}$ In 1950s horwich and usher used prosthetic materials $(2.5 \mathrm{~cm} \times 7 \mathrm{~cm})$ for treating inguinal and incisional hernias. ${ }^{[5,6]}$ Up to mid-1980s there has been increase in the use of prosthetic mesh in surgery for hernia.

Lichtenstein (1974) began using a rolled or cylindrical or cigarette mesh plug for treatment of inguinal hernia, femoral and recurrent hernias with the aim of avoiding suture line tension. Gilbert (late 1980s) used a flat piece of mesh into a cone or umbrella shape to close the defect. Learning of his success with this technique, Rutkow and Robbins (1989) began using hand fashioned umbrella plugs. By the end of 1991 they were using mesh plugs to treat all types of inguinal hernias. Since 1993 they have started using pre manufactured umbrella "marlex mesh" and found it simpler to use than a man - fashioned mesh. ${ }^{[7]}$ Tension free mesh repair for inguinal hernia reported less pain, shorter hospitalization, lower recurrence and early return to work after surgery. ${ }^{[8]}$

With the advent of laparoscopy entering every field of surgery, laparoscopic hernia repair was the obvious next sTEP but unlike laparoscopic cholecystectomy, laparoscopic hernia repair took 16 yrs for a market penetration of $5-15 \%$ in the developed world. ${ }^{[9]}$

The most common laparoscopic hernia repairs now are TAPP, TEP and IPOM. Both TAPP and TEP have the basic principle of placing a piece of mesh in the pre peritoneal space described by stoppa. ${ }^{[10]}$

Laparoscopic hernia repair is associated with less postoperative pain and early ambulation but it is more expensive, takes longer time to perform. ${ }^{[11]}$ Studies showed that open 
mesh repair had more advantages, reference to cost, recurrence and vascular complications, ${ }^{[12]}$ than laparoscopic repair. In the past, only recurrence rate was taken in to account as the first goal in hernia repairs. Today, laparoscopic or open routes, new challenges have to be faced to obtain not only a solid repair with low morbidity and mortality rates, but also a pain less post-operative period, short hospital stay, an inexpensive technique, a technique easy to teach and feasibility of carrying out repairs by every surgeon. ${ }^{[13]}$

So far till date, there is no ideal operative procedure for inguinal without any complications that are, postoperative pain, postoperative infections, recurrence and cost effectiveness. Each type of repair had its own advantages and disadvantages.

\section{Aims and Objectives}

1) To compare laproscopic inguinal hernia repair and open inguinal hernia repair with regards to post-operative pain ,surgical site infections ,hospital stay and time taken to return to work, by a randomized study.

2) To compare outcome with regards to post-operative complications and recurrence

\section{Subjects and Methods}

Type of Study: Randomised prospective blinded study.

Study Area: Kamineni Hospitals, LB Nagar, Hyderabad.

Study Group: 50

Study Period: October 2010 to August 2012

\section{Inclusion Criteria}

Age $(>18$ yrs $)$, Inguinal hernias Unilateral/ bilateral, Direct/indirect

\section{Exclusion Criteria}

Recurrent hernias, Complicated hernias, Patients who has not given consent, Pediatric age group $(<18$ yrs $)$

Pain scoring [Figure 1]:

Vas is a $10 \mathrm{~cm}$ horizontal line labeled as 'no pain' at one end and 'worst pain imaginable' on the other end. The patient is asked to mark on this line where intensity of pain lies. The distance form 'no pain' to the patient's mark numerically quantifies the pain.

\section{Verbal rating scale (vrs) ${ }^{[14]}$}

Pain as expressed by the patients with their own language, verbal rating scale was rated as $0-10$

0 - no pain

1-2 - mild pain

3-5 - moderate pain

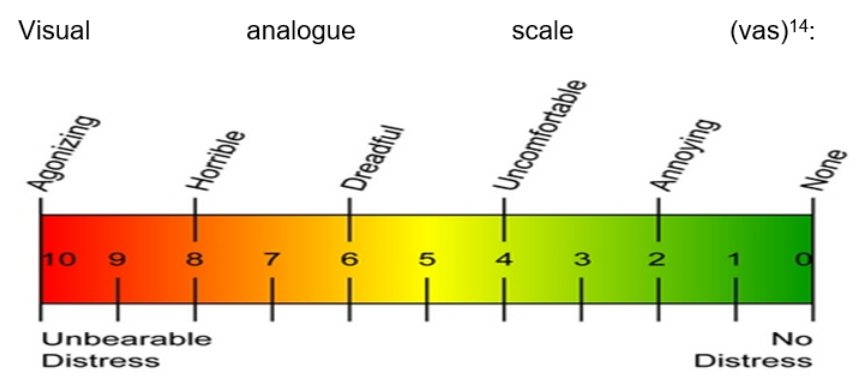

Figure 1: VAS Score

6-7 - severe pain

8-10 - unbearable pain

Results

Fifty patients of uncomplicated inguinal hernia, aged between 15-65 yrs, of either sex, were randomly selected and scheduled to undergo elective hernia repair under general or regional anaesthesia, like open mesh repair and laparoscopic mesh repair were included in this study.

After randomization,25 patients were underwent open mesh hernia repair and 25 patients underwent laparoscopic hernia repair.

$29(59 \%)$ were right sided (open mesh 14 and laparoscopic 15 ) and $41 \%$ were left sided (openmesh 11 and laparoscopic 10). 52\% were direct type (openmesh 12 and laparoscopic 14) and $48 \%$ were indirect type (openmesh 13 and laparoscopic 11). $12(48 \%)$ were direct type with right (8) and left (4) side distribution.13 (52\%) were indirect type with right(6) and left(7) distribution.14 (56\%) were direct type with right (8) and left (6) side distribution and11(44\%) were indirect type with right (6) and left (5) side distribution.

Laparoscopic repair (95.24 $\mathrm{min})$ requires longer time to perform than open mesh repair $(91.20 \mathrm{~min})$ with $\mathrm{p}$ value of 0.5825 .

\section{Visual Analogue Scale (VAS) on the day of surgery}

Lap repair group had less pain score than others. After $1 \mathrm{hr}$ of surgery with $p$ value 0.1033 . Laproscopic group had less pain score than open After 6hrs of surgery with $p$ value of 0.272 . Laparoscopic group had less pain score than open group. After $12 \mathrm{hrs}$ of surgery with 0.2014 . Lap repair group had less pain score than open repair group. After $24 \mathrm{hrs}$ of surgery with $\mathrm{p}=0.296$.

All categorical variables were represented as means \pm sd and were compared using student ' $t$ ' test-recording of hourly measurement such as vas on both groups repeated measures 


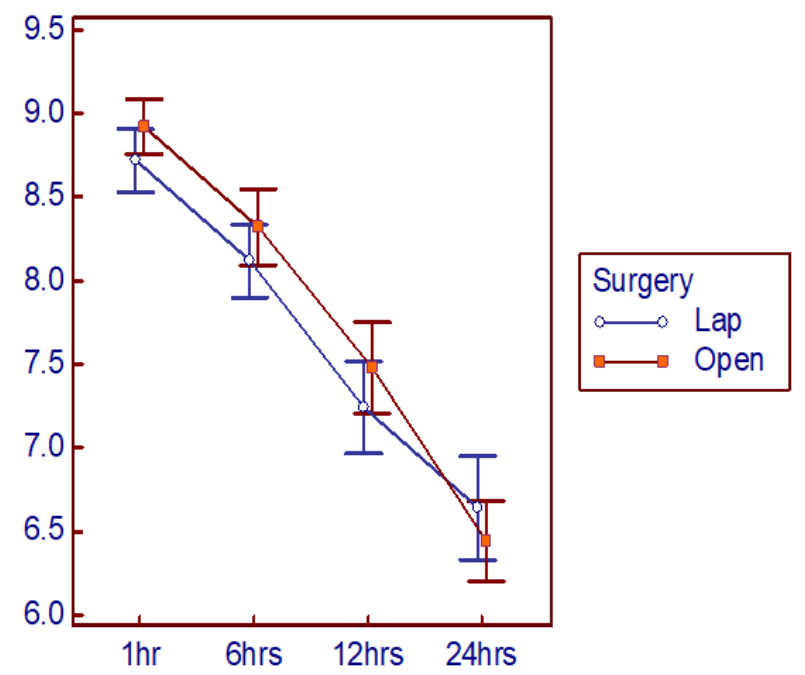

Figure 2: Open Vs Lap Surgery

anova-no difference $(\mathrm{p}<0.27)$ fig-2.

\section{Verbal Rating Scale (VRS)}

Laparoscopic repair had less pain scores after $12 \mathrm{hrs}$ of $1 \mathrm{st}$ pod compared to others with $p$ value of 0.115 . Laparoscopic repair had less pain score after $24 \mathrm{hrs}$ of 1 st pod compared to others with $p$ value of 0.133 .

Table 1: Comparison of complications on the immediate postoperative period during hospital stay

\begin{tabular}{lll}
\hline Complication & Open mesh (25) & Lap repair (25) \\
Seroma & $9 / 25-36 \%$ & $3 / 25-12 \%$ \\
Wound infection & $6 / 25-24 \%$ & $4 / 25-16 \%$ \\
Fever & $5 / 25-20 \%$ & $2 / 25-8 \%$ \\
Urinary retention & $0 / 25-0$ & $5 / 25-20 \%$ \\
$\begin{array}{l}\text { Operation site } \\
\text { pain }\end{array}$ & $24 / 25-96 \%$ & $20 / 25-80 \%$ \\
Scrotal pain & $20 / 25-80 \%$ & $15 / 25-60 \%$ \\
\hline
\end{tabular}

\section{Requirement of Analgesic Drug (Number)}

Laparoscopic repair group required less analgesicon the day of surgery compared to open repair group with $p$ value of 0.339 . Laparoscopic repair group require less analgesic on the $1 \mathrm{st}$ pood compared to open repair group with $p$ value of 0.66

Operative site pain and scrotal pain were most common immediate post-operative complication in both the groups. Seroma and wound infection were common in open mesh repair $(36 \%)$. Fever was common in open mesh repair than in laparoscopic group.

\section{Total Duration Hospital Stay: (In Days)}

Laparoscopic group patients had less no of hospital stay than open mesh repair group

\section{Return To Daily Activities After Surgery: (In Days)}

Return to daily activities was earlier in laparoscopic group than open repair group with $p$ value 0.627

\section{Return To Regular Work After Surgery: (In Days)}

Return to regular work was earlier in laparoscopic mesh repair group than open repair with mesh with $\mathrm{p} 0.011$

\section{Complications on $7^{\text {th }}$ POD}

Inguinal pain (operation site) was common complaint in all groups of patients in 7 th pod $32 \%$ in open mesh repair, $20 \%$ in laparoscopic repair. Seroma was common in open mesh repair group (20\%), $8 \%$ in laparoscopic repair. Requirement of daily dressings were common in open mesh repair group (24\%) than laparoscopic repair (8\%). Wound infection seen in $8 \%$ of open mesh repair group and laparoscopic repair (4\%)

\section{Complications in Follow UP}

During follow up scrotal hematoma was seen in 1(4\%) patients of open repair group. Recurrence was seen two patients $(8 \%)$ of laparoscopic repair.

\section{Discussion}

Surgery for inguinal hernia is the most commonly and frequently performed operation in general surgery. The best approach to inguinal hernia repair is yet to be defined. The multitude of number of operations confirms that only some of them satisfy the criteria of ideal inguinal hernia repair.Hence a need was felt to compare the two most popular approaches, open mesh hernia repair and laparoscopic hernia repair, by a rct at Kamineni hospitals, Hyderabad. Primary end points of this rct were targeted at short-term results. The following parameters of short term results were evaluated in this rct, they are the duration of operation, post-operative pain, analgesic requirements on the day of surgery and first post-operative day, hospital stay after surgery and total duration of hospital stay, return to daily and normal activities, post-operative complications and recurrence after the surgery.

The study was comprised of only men (50), right sided was seen in 59\% and left sided was in $41 \%$. Male preponderance and right-sided preponderance was also seen in series of clarks aston key work (nchs - 1979) as well as analysis of hernia center during 1989 - 9716.

The duration of operation did not differ significantly in all the groups $(p=0.5825)$. Laparoscopic repair took at an average of $95.24 \mathrm{~min}$, while open mesh repair took $91.20 \mathrm{~min}$. Horeyseck et al, ${ }^{[15]}$ also showed no significant statistical time difference between laparoscopic and lichtenstein technique 
in their prospective study. While mc cormark et al (laparoscopic repair $14.8 \mathrm{~min}$ longer than open repair, $\mathrm{p}<0.0001$ ), memon (laparoscopic repair 15.2min longer than open mesh repair, $p<0.0001$ ) and others reported significant increased duration with laparoscopic repair as compared to open mesh repair, the difference was statistically significant in all these studies. ${ }^{[16-18]}$

Pain was common after any surgical procedure. The pain scale is one tool commonly used to describe the intensity of the pain or how much pain the patient is feeling. The pain scales include the numerical rating scale, the visual analog scale, the categorical scale, and the pain faces scale.

In the present study postoperative pain was compared using vas and vrs. The vas was a well-studied method for assessing acute pain and its usefulness was validated by several studies. ${ }^{[19]}$ Wewers \& lowe (1990), ${ }^{[20]}$ described the benefits of the vas which is highly subjective; these scales are of most value when looking at change within individuals.

In laparoscopic repair vas was less in the $1^{\text {st }} \mathrm{hr}$, 6hrs and 12 hrs of operation as compared to that of open mesh repair but this was not statistically significant $(p=0.1033, p=0.272$ , $\mathrm{p}=0.2014$ respectively). Filipi et al, ${ }^{[21]}$ wilson et al, ${ }^{[22]}$ barth et al, ${ }^{[23]}$ shmitz et al, ${ }^{[24]}$ barkun et al and maddern et al using vas and other scores showed similar results in the immediate postoperative period.

Long-term pain was less when synthetic mesh was used as showed by eu hernia trialists collaboration in 2002 with their analysis of 15 trials. ${ }^{[25]} 2002$ updated analysis of eu hernia trialist collaboration showed laparoscopic repair was associated with less postoperative pain compared to open hernia repair but the difference was not statistically significant. ${ }^{[26]}$

Kozol et al, ${ }^{[27]}$ stocker et al, champault et al, schrenk et al, tschudi et al, lawrence et al, wright et al, leim et al, and bessells et al, in their rct showed significant reduction of pain in laparoscopic group compared to open non mesh repair $(\mathrm{p}<$ $0.05)$. Heikkinen et al showed that laparoscopic TAPP repair was less painful as compared to lichtenstein repair $(\mathrm{p}<0.05)$. Bittner et al, ${ }^{[28]}$ also confirmed the same in their meta-analysis of ret of comparison of laparoscopic repair (TAPP/TEP) with shouldice and other non-mesh techniques showed.

Post-operative pain after $12 \mathrm{hrs}(\mathrm{p}=0.115)$ and $24 \mathrm{hrs}(\mathrm{p}=0.133)$ on the very first pod was less in laparoscopic in the present study although it was not statistically significant.

Analgesic requirement (number) on the day of surgery was not significantly $(\mathrm{p}=0.339)$ different in either of these techniques and this was in tandem with the experience of Barth et al, ${ }^{[23]}$ brooks and Filipi et al. ${ }^{[21,29]}$

First pod analgesic requirement (number) also did not show significant difference $(\mathrm{p}=0.66)$, contrary to the Juul et $\mathrm{al},{ }^{[30]}$ reported shorter period of analgesic requirement in laparoscopic repair as compared to open hernia repair (2.1 vs $2.7, \mathrm{p}<0.02$ ).

Hospital stay also did not differ significantly $(p=0.20)$, although the mean duration of stay was least in laparoscopic group as compared to open mesh repair group. Memon et $\mathrm{al}^{\left[{ }^{[31]}\right.}$ in their meta-analysis of rct showed shorter hospital stay in laparoscopic group (3.43 hrs, $\mathrm{p}=0.029)$ than open method similar to observation of the present study.

Return to daily activities (days) was earlier in laparoscopic repair (2.48) than in open mesh repair group(2.56), but this is not statistically significant ( $\mathrm{p}=0.627$ ).

Return to normal work (in days) was earlier in laparoscopic repair (10.72) as compared to open mesh repair (12.76) and the difference was statistically significant $(\mathrm{p}=0.011)$.

Bittner $r$ et al, ${ }^{[28]}$ showed TAPP had shorter postoperative recovery time and return to normal work as compared to those who had open non mesh repair. Memon et al, ${ }^{[31]}$ showed a statistically significant difference in return to daily activities (4.73 days, $\mathrm{p}<0.001$ ) and normal work (6.96 days, $\mathrm{p}<0.001$ ) in laparoscopic repair than open mesh repair. Studies 24, also also concurred with the results of the present study and showed the similar results.

Patient who underwent open mesh repair had earlier return to normal work than those with laparoscopic repair in horeyseck

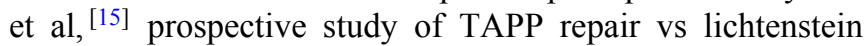
repair ( $p>0.05)$ this observation was not in concordance with the present study which showed laparoscopic repair had earlier return to normal work than open mesh repair.

Seroma was common in open mesh repair (36\%) than laparoscopic repair (12\%) in immediate post-operative period, in contrast to bittner at al, ${ }^{[28]}$ laparoscopic vs open non mesh repair (seroma is less common in open non mesh repair). Seroma formation in laparoscopic repair was reported $1.2 \%$ $-10 \%$ by felix et al and massaad et al. ${ }^{[32]}$

Wound infection was common in open mesh repair (24\%), than in laparoscopic repair (16\%) in immediate post-operative period, as in sauerland et al, conclusion of significant decrease of wound infection in laparoscopic repair than open mesh repairs. Amid pk, ${ }^{[33]}$ and Kark, ${ }^{[34]}$ open mesh repairs had $0.6 \%$ and $1.3 \%$ of wound infection rates respectively.

Fever (20\%), operation site pain (96\%) were common in open mesh repair than to others in immediate post-operative period. Over all complications in open mesh repair were $38.85 \%$ and laparoscopic repair were $36 \%$, similar to filipi et al, ${ }^{[21]} \mathrm{kozol}$ et al, ${ }^{[27]}$ laparoscopic repair and open mesh repair.

All patients were followed on 7th pod and regular 1,2,3weeks and 3 months intervals. On 7th pod persistence of seroma was common in open mesh repair (20\%), compared to laparoscopic repair $(8 \%)$. Inguinal pain was common in open mesh repair 
(32\%) and wound infection of $8 \%$ observed in open mesh repair. Hematoma was common in open mesh repair (4\%).

Laparoscopic hernia repair had significantly higher number of complications (vascular and visceral) than open mesh repair as experienced by leigh et al, ${ }^{[35]} \mathrm{mrc}$ trial group20 and $\mathrm{mc}$ cormack et al, ${ }^{[36]}$ cochrane data base review 2003. No such complications were encountered in the present study.

Recurrence of hernia occurred in 2 patients after laparoscopic repair $(2 / 25-8 \%)$ compared with open mesh $(0 \%)$. Similar to others studies. ${ }^{[18,30,35]}$

Rate of recurrence after laparoscopic repair was $<1 \%$. ${ }^{[37,38]}$ Angelescu et al, ${ }^{[39]}$ stocker et al, schrenk et al found $0 \%$ recurrence in laparoscopic repair and open non mesh repair (table 6) contrast to the observations of present study. Butters et $\mathrm{al},{ }^{[25]}$ in their study of 280 patients, recurrence of hernia occurred in 6 patients after shouldice repair, 1 in each in lichtenstein and TAPP with a follow up of 52 weeks.

\section{Conclusion}

Laparoscopic mesh hernioplasty still remains to be validated with larger number of patients and longer duration of follow up.

\section{References}

1. Lassandro F, Iasiello F, Pizza NL, Valente T, di Santo Stefano MLM, Grassi R. World J Gastrointest Endosc. Abdominal hernias: Radiological features. 2011;3(6):110-117. doi:10.4253/wjge.v3.i6.110.

2. Udwadia TE. Inguinal hernia repair: The total picture. Inguinal hernia repair: The total picture. 2006;2(3):144-146.

3. Bassini E. Sulla cura radicale dill'ernia inguinale. Arch Soc Ital Chir. 1887;4:380-380.

4. Stock F. REPAIR OF LARGE HERNIÆWITH NYLON MESH. Elsevier BV; 1954. Available from: https://dx. doi.org/10.1016/s0140-6736(54)90930-7. doi:10.1016/s01406736(54)90930-7.

5. Horwich M. Hernia repair using nylon tricot implant. Br J Surg. 1958;45(192):320-322. doi:10.1002/bjs. 18004519204.

6. Usher FC. Marlex Mesh, a New Plastic Mesh for Replacing Tissue Defects. AMA Arch Surg. 1959;78:138-138. Available from: https://dx. doi.org/10.1001/archsurg.1959.04320010140023. doi:10.1001/archsurg.1959.04320010140023.

7. Robbins AW, Rutkow IM. Mesh Plug Repair and Groin Hernia Surgery. Surg Clin North Am. 1998;78(6):10071023. Available from: https://dx.doi.org/10.1016/s00396109(05)70366-2. doi:10.1016/s0039-6109(05)70366-2.

8. Lichtenstein IL, Shulman AG, Amid PK, Montllor MM. The tension-free hernioplasty. Am J Surg. 1989;157:188-193. Available from: https://dx.doi.org/10.1016/0002-9610(89) 90526-6. doi:10.1016/0002-9610(89)90526-6.

9. Ravindran R, Bruce J, Debnath D, Poobalan A, King PM. A United Kingdom survey of surgical technique and handling practice of inguinal canal structures during hernia surgery. Surg. 2006;139(4):523-526. Available from: https://dx.doi.org/10.1016/j.surg.2005.09.008. doi:10.1016/j.surg.2005.09.008.

10. Stoppa RE. The treatment of complicated groin and incisional hernias. World J Surg. 1989;13:545-554. Available from: https://dx.doi.org/10.1007/bf01658869. doi:10.1007/bf01658869.

11. Collaboration EHT. Repair of groin hernia with synthetic mesh: meta-analysis of randomized controlled trials. Ann Surg. 2002;235(3):322-332. doi:10.1097/00000658-20020300000003.

12. Wellwood J, Sculpher MJ, Stoker D, Nicholls GJ, Geddes C, Whitehead A, et al. Randomised controlled trial of laparoscopic versus open mesh repair for inguinal hernia: outcome and cost. Br Med J. 1998;317(7151):103-110. Available from: https://dx.doi.org/10.1136/bmj.317.7151.103. doi:10.1136/bmj.317.7151.103.

13. Debord JR. Abdominal wall Hernias. In: R BD, J A, MF A, editors. Prostheses in hernia surgery: a century of evolution. New York, NY: Springer; 2001. p. 16-32. doi:doi=10.1007/978-1-4419-8574-3_3.

14. Follin SL, Charland SL. Acute pain management: operative or medical procedures and trauma. Ann Pharmacother. 1997;31(9):1068-76. doi:10.1177/106002809703100917.

15. Horeyseck G, Roland F, Rolfes N. Die „, spannungsfreie“ Reparation der Leistenhernie: laparoskopisch (TAPP) versus offen (Lichtenstein). Der Chirurg. 1996;67:1036-1040. Available from: https://dx.doi.org/10.1007/s001040050100. doi:10.1007/s001040050100.

16. Gottlieb S. Open surgery better than laparoscopic for repair of inguinal hernia. Br Med J. 2004;328(7447):1033.

17. Wright DM, Kennedy A, Baxter JN, Fullarton GM, Fife LM, Sunderland GT, et al. Early outcome after open versus extraperitoneal endoscopic tension-free hernioplasty: A randomized clinical trial. Surg. 1996;119(5):552-557. Available from: https://dx.doi.org/10.1016/s0039-6060(96)80266-2. doi:10.1016/s0039-6060(96)80266-2.

18. Laparoscopic versus open repair of groin hernia: a randomised comparison. Lancet. 1999;354(9174):185-90. doi:10.1016/S0140-6736(98)10010-7.

19. Katz J. Measurement of pain. Surg Clin North Am. 1999;79:231-52.

20. Wewers ME, Lowe NK. A critical review of visual analogue scales in the measurement of clinical phenomena. Res Nursing Health. 1990;13:227-236. Available from: https://dx.doi.org/ 10.1002/nur.4770130405. doi:10.1002/nur.4770130405.

21. Filipi CJ, Gaston-Johansson F, McBride PJ, Murayama K, Gerhardt J, Cornet DA, et al. An assessment of pain and return to normal activity. Surg Endosc. 1996;10(10):983-986. Available from: https://dx.doi.org/10.1007/s004649900219. doi:10.1007/s004649900219.

22. Wilson MS, Deans GT, Brough WA. Prospective trial comparing Lichtenstein with laparoscopic tension-free mesh repair of inguinal hernia. Br J Surg. 1995;82(2):274-277. Available from: https://dx.doi.org/10.1002/bjs.1800820245. doi:10.1002/bjs. 1800820245 . 
23. Barth RJ, Burchard KW, Tosteson A, Sutton JE, Colacchio TA, Henriques HF, et al. Short-term outcome after mesh or Shouldice herniorrhaphy: A randomized, prospective study. Surg. 1998;123(2):121-126. Available from: https://dx. doi.org/10.1016/s0039-6060(98)70247-8. doi:10.1016/s00396060(98)70247-8.

24. Schmitz R, Treckmann J, Shah S, Schneider K. Tensionfree technique" in open inguinal hernia repair. A prospective, randomized study of postoperative pain perception (" tensionfree reconstruction" vs. Shouldice technique). Zeitschrift fur alle Gebiete der operativen Medizen. 1997;68(3):259-63.

25. Hernia EU. Trialists Collaboration Mesh compared with nonmesh methods of open groin hernia repair: systematic review of randomized controlled trials. Br J Surg. 2000;87:854 863.

26. Repair of groin hernia with synthetic mesh: meta-analysis of randomized controlled trials. . Ann Surg. 2002;235:322-322. doi:10.1097/00000658-200203000-00003.

27. Kozol R, Lange PM, Kosir M, Beleski K, Mason K, Tennenberg $\mathrm{S}$, et al. A prospective, randomized study of open vs laparoscopic inguinal hernia repair: an assessment of postoperative pain. Arch Surg. 1997;132(3):292-297. doi:10.1001/archsurg.1997.01430270078015.

28. Bittner R, Sauerland S, Schmedt CG. Comparison of endoscopic techniques vs Shouldice and other open nonmesh techniques for inguinal hernia repair: a meta-analysis of randomized controlled trials. Surg Endosc. 2005;19:605-615. Available from: https://dx.doi.org/10.1007/s00464-004-90499. doi:10.1007/s00464-004-9049-9.

29. Brooks DC. A prospective comparison of laparoscopic and tension-free open herniorrhaphy. . Arch Surg. 1994;129:361367. doi:10.1001/archsurg.1994.01420280031004.

30. Juul P, Christensen K. Randomized clinical trial of laparoscopic versus open inguinal hernia repair. Br J Surg. 1999;86:316319. Available from: https://dx.doi.org/10.1046/j.1365-2168. 1999.01053.x. doi:10.1046/j.1365-2168.1999.01053.x.

31. Memon MA, Cooper NJ, Memon B, Memon MI, Abrams KR. Meta-analysis of randomized clinical trials comparing open and laparoscopic inguinal hernia repair. Br J Surg. 2003;94:147992. doi:10.1002/bjs. 4301.

32. David. Laparoscopic repair and groin hernia surgery. Surg Clin North Am. 1998;78(8):1052-1059.

33. Shulman AG, Amid PK, Lichtenstein IL. A survey of nonexpert surgeons using the open tension-free mesh patch repair for primary inguinal hernias. Int Surg. 1995;80(1):35-36.

34. Kark AE, Kurzer MN, Belsham PA. Three Thousand One Hundred Seventy-Five Primary Inguinal Hernia Repairs: Advantages of Ambulatory Open Mesh Repair Using Local Anesthesia. J Am Coll Surg. 1998;186(4):447-455. Available from: https://dx.doi.org/10.1016/s1072-7515(98)00057-x. doi:10.1016/s1072-7515(98)00057-x.

35. Neumayer L, Giobbie-Hurder A, Jonasson O, Fitzgibbons R, Dunlop D, Gibbs J, et al. Open Mesh versus Laparoscopic Mesh Repair of Inguinal Hernia. New England Journal of Medicine. 2004;350(18):1819-1827. Available from: https://dx.doi.org/ 10.1056/nejmoa040093. doi:10.1056/nejmoa040093.

36. McCormack K, Scott N, Go PMNYH, Ross SJ, and AG. Laparoscopic techniques versus open techniques for inguinal hernia repair. Cochrane Database of Systematic Reviews. 2003;(1). Available from: https://dx.doi.org/10.1002/ 14651858.cd001785. doi:10.1002/14651858.cd001785.

37. Felix E, Scott S, Crafton B, Geis P, Duncan T, Sewell R, et al. Causes of recurrence after laparoscopic hernioplasty. Surg Endosc. 1998;12:226-231. Available from: https://dx.doi.org/ 10.1007/s004649900640. doi:10.1007/s004649900640.

38. Schmedt CG, Däubler P, Leibl BJ, Kraft K, Bittner R. Simultaneous bilateral laparoscopic inguinal hernia repair. Surg Endosc Intervent Tech. 2002;16:240-244. Available from: https:// dx.doi.org/10.1007/s00464-001-8184-9. doi:10.1007/s00464001-8184-9.

39. Angelescu N, Jitea N, Burcoş T, Cristian D, Voiculescu S, Dimitriu C. A comparative study of the laparoscopic and classic treatments of inguinal hernias. Chirurgia. 1990;45(5):267-70.

Copyright: (C) the author(s), 2020. It is an open-access article distributed under the terms of the Creative Commons Attribution License (CC BY 4.0), which permits authors to retain ownership of the copyright for their content, and allow anyone to download, reuse, reprint, modify, distribute and/or copy the content as long as the original authors and source are cited.

How to cite this article: Ilyas M, Cholleti VV. Prospective Randomized Blinded Study to Compare Laparoscopic and Open Inguinal Hernioplasty. Acad. J Surg. 2020;3(1):149-154.

DOI: dx.doi.org/10.47008/ajs/2020.3.1.32

Source of Support: Nil, Conflict of Interest: None declared. 